\title{
Chest wall sarcoma of childhood with a good prognosis
}

\author{
A. J. BARSON, A. AHMED, A. A. M. GIBSON, AND A. M. MACDONALD
}

From the Departments of Pathology, University of Manchester, and Royal Hospital for Sick Children, Glasgow

SUMMARY Four cases of a locally invasive sarcoma of the chest wall are described in children aged between 8 and 14 years. Although its morphology resembles a Ewing's sarcoma of bone there are light and electron microscopical features that are distinctive. The sarcoma is thought to represent an entity which has not previously been defined. Its clinical importance lies in the fact that the prognosis with appropriate treatment appears to be good. One child died after $2 \frac{1}{2}$ years, but the others are alive 6,8 , and 16 years after presentation.

A wide variety of both benign and malignant tumours arise within the wall of the chest, peripheral to the lung and pleural cavity although they may secondarily invade it. These heterogeneous tumours are often considered as a group because of the similarity of diagnostic and therapeutic problems which they represent. Approximately $8 \%$ of all primary bone tumours arise in the ribs or sternum (Teitelbaum, 1972a), and the same proportion $(8 \%)$ of all soft tissue sarcomas occur within the chest wall (Teitelbaum, 1972b). There are several large surveys of chest wall tumours (Hedblom, 1921; Hochberg, 1953; Pascuzzi et al., 1957; Watkins and Gerard, 1960; Teitelbaum, 1969; Threlkel and Adkins, 1971), and although childhood cases are quoted they represent a minority. Of 339 patients with malignant tumours of the chest wall reviewed by Watkins and Gerard (1960) only 2 were under 20 years. Similarly Hedblom (1921), in a series of bony chest wall tumours, found only 28 cases under 20 years out of 213 patients, and Hochberg (1953) reported 39 among 205 cases of primary rib tumour.

There have been comparatively few studies specifically of childhood chest wall tumours. Joseph and Fonkalsrud (1972) reviewed reports of these and contributed 4 of their own cases seen over a 10-year period. Chondromas and osteochondromas were the commonest benign chest wall tumours found in children, followed by osteoma, osteoid osteoma, eosinophilic granuloma, giant cell tumour, fibrous dysplasia, and aneurysmal bone cyst. Of the malignant rib tumours, as with adults, chondrosarcoma

Received 13 March 1978 was the commonest. Osteogenic sarcoma, lymphosarcoma, fibrosarcoma, Ewing's sarcoma, and Hodgkin's disease were all found in children. The radiographic features of tumours of the chest wall in children were described by Franken et al. (1977). Ewing's sarcomata was the only primary thoracic malignancy in their series.

Chest wall tumours in the 4 children (Cases 1-4) attracted interest initially because of their characteristic histological morphology. Although they were clearly all the same type of tumour it was impossible to place them among other known categories of neoplasia. All were locally invasive, originating in the soft tissues of the thorax, and appearing to involve bone secondarily. Only one child (Case 4) died after local recurrence and abdominal metastasis. The excellent clinical course after treatment in Cases 1-3 lends further support to the histopathological impression that this type of tumour is an entity distinct from other chest wall sarcomata seen in childhood, and especially from Ewing's tumour to which it has some resemblance.

\section{Case reports}

Case 1. This girl presented at 14 years with a history of an intermittent, dull, aching pain over the right side of the chest of 6 months' duration. $X$-ray demonstrated a large rounded opacity in the right midzone of the chest wall. She had been treated as a case of pulmonary tuberculosis without improvement. At thoracotomy a tumour measuring $7 \times$ $5.5 \times 5 \mathrm{~cm}$ was removed which was attached to the inner aspects of the 6th, 7th, and 8th ribs (Fig. 1). Radiologically there was seen to be some erosion 


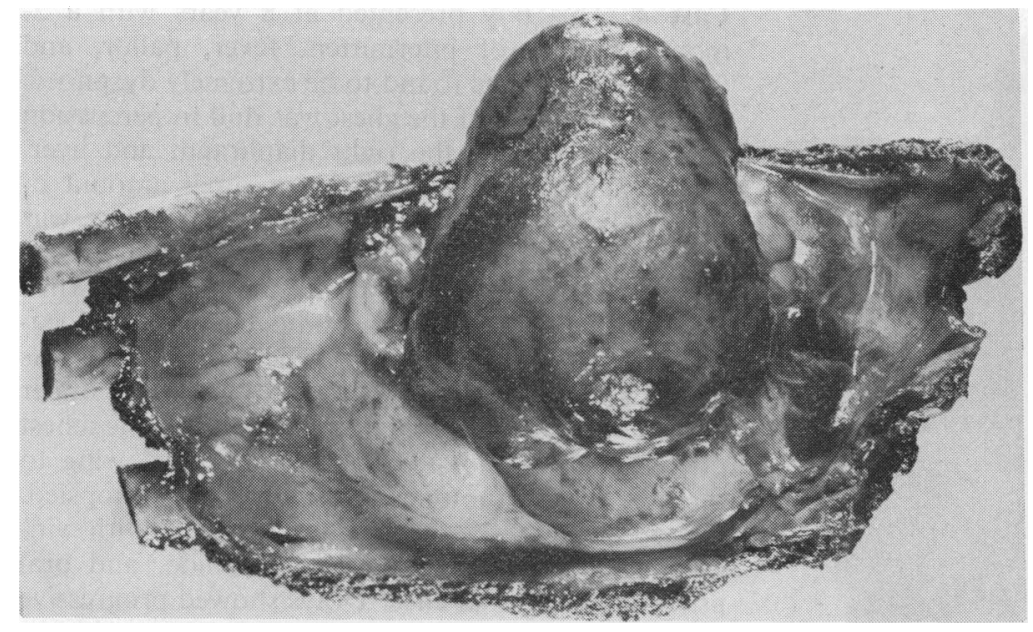

Fig. 1 Case 1. Tumour adherent to the inner aspect of $6 \mathrm{th}, 7 \mathrm{th}$, and 8 th ribs. $\times 0.7$.

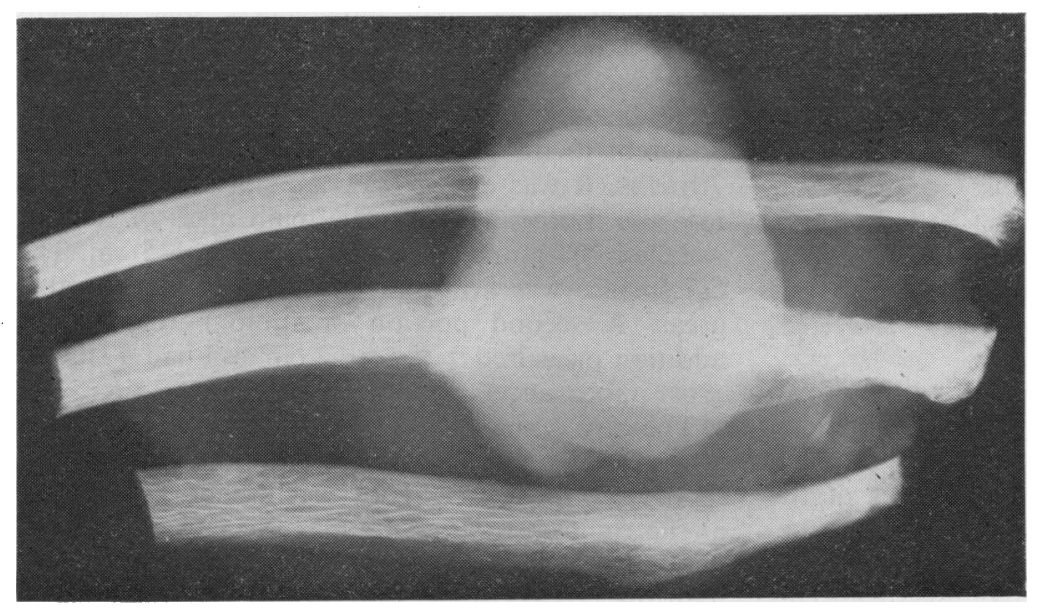

Fig. 2 Radiograph of the surgical specimen in Fig. 1 showing periosteal reaction around the ribs. $\times 0 \cdot 7$.

and periosteal reaction of the ribs (Fig. 2), but there was no evidence of tumour elsewhere within the thorax. Grossly a thin capsule enclosed a fleshy haemorrhagic greyish-yellow tumour. The outer one-third adjacent to the ribs was homogeneous and firm while the remainder displayed numerous vascular channels.

She was given radiotherapy postoperatively followed by a course of vincristine and cyclophosphamide. She has remained well with no sign of recurrence 8 years later at age 22 .

Case 2. This 8-year-old girl was admitted to hospital with a hard swelling maximal over the anterior aspect of the right 5th rib. She was an apparently healthy child without history of pain or weight loss.

An $x$-ray showed a large mass situated mainly anteriorly within the right thorax, but extending into the mediastinum. Speckled calcification was seen in the centre of the tumour and the overlying end of the right 5th rib was expanded and eroded. Occult spina bifida of the 6th cervical vertebra was noted.

At operation an encapsulated tumour was removed, together with a $5 \mathrm{~cm}$ portion of the extremity of the 5th rib. Lung tissue was easily separated from the mass. The soft, fleshy, well-circumscribed tumour (Fig. 3) measured $14 \times 10 \times 8 \mathrm{~cm}$ and the cut surface displayed areas of haemorrhage and necrosis within a solid pale background. Although intercostal muscle and bone were infiltrated by tumour, a portion of the contiguous lung measuring $8 \times 6 \times 3 \mathrm{~cm}$ showed no evidence microscopically of invasion. The patient was irradiated postoperatively and was well with no recurrence 16 years later at age 24 . 


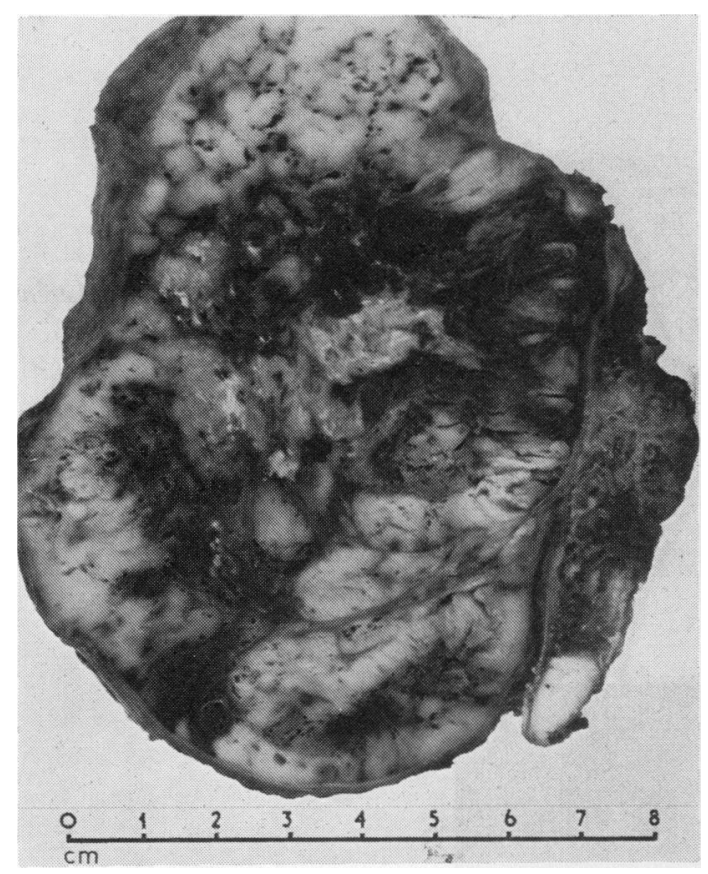

Fig. 3 Cut surface of the sarcoma removed from Case 2. Numerous small vascular channels can be seen.

Rib on the right is not invaded. $\times 0.75$.

Case 3. This 11-year-old girl presented with a cough of 8 weeks' duration and a continuous right-sided chest pain for the previous 4 . More recently walking had made her breathless. The greater part of the right side of the chest was radiologically opaque. Bronchoscopy showed complete occlusion of the right main bronchus from external pressure. This was followed by a thoracotomy when an enormous, semisolid, semicystic mass was removed which had occupied approximately seven-eighths of the right thorax. This entailed a right upper and middle lobectomy, but the tumour remained in an area around the costochondral junction of the 2nd and 3 rd rib where the chest wall was infiltrated. The two excised lobes weighed $800 \mathrm{~g}$. The cut surface showed a complete replacement of the normal pulmonary architecture by a friable, haemorrhagic, cystic tumour. Postoperatively the patient was treated by irradiation and vincristine, doxorubicin, and cyclophosphamide chemotherapy. The right lower lobe expanded and postoperative pneumothorax resolved satisfactorily. There was no radiological evidence of tumour in the chest wall or within the lung 11 months after surgery. When last seen 6 years after surgery at age 17 she was well, although there was lack of development of the right breast.
Case 4. This boy presented at 8 years with a 2month history of intermittent fever, pallor, and listlessness. He was found to be extremely dyspnoeic and the right side of the chest was dull to percussion with depression of the right diaphragm and liver. Pleural aspiration yielded only a small amount of blood and no tumour cells were seen. There was evidence of thoracic outlet obstruction with grossly dilated veins over the thorax and upper arms. Radiologically there was a homogeneous opacification of the right hemithorax. The right 7 th rib was thought to be eroded, and probably also the upper dorsal vertebral bodies. Exploration of the chest proved to be impossible at thoracotomy owing to the size of the tumour so this was only biopsied. Postoperatively the patient was treated with vincristine, doxorubicin, cyclophosphamide, and oral procarbazine. Serial chest $x$-rays showed progressive reduction in the opacity in the right chest with reexpansion of the right lung. There was sufficient improvement to enable a surgical resection to be performed through a right thoracotomy 15 weeks after beginning chemotherapy. The tumour was adherent to the posterior part of the 5th, 6th, and 7th ribs. It was extrapleural and pushing forwards into the thoracic cavity. The main mass of tumour weighed $200 \mathrm{~g}$ and measured $11 \times 8 \times 5 \mathrm{~cm}$. The cut surface was firm and grey with brown necrotic areas. A second portion of tumour removed in addition measured $9 \times 5 \times 3 \mathrm{~cm}$ and had a similar gross appearance.

The boy remained free of tumour for 20 months after the resection, while continuing on chemotherapy, until a recurrence was seen radiologically at the right costophrenic angle. A mass of tumour, about the size of a golf ball, was resected together with the related diaphragm. A further thoracotomy was performed one month later because of recurrent tumour of the chest wall. The right middle and lower lobes of the lung were adherent to the tumour and were resected but no tumour infiltration was demonstrated. Chemotherapy was not restarted after these 2 operations. There followed paravertebral spread of tumour below the diaphragm, confirmed surgically to extend down to the level of the renal vessels. A course of radiotherapy was given to the chest and abdomen. However there was progressive deterioration and he died 3 months later, 29 months after presentation at hospital. Necropsy was not performed.

Histology. The light microscopical appearance of the chest wall tumour from all 4 patients was essentially similar. The tumour was composed of sheets of undifferentiated cells in which were numerous irregular vascular spaces (Fig. 4). Apart 


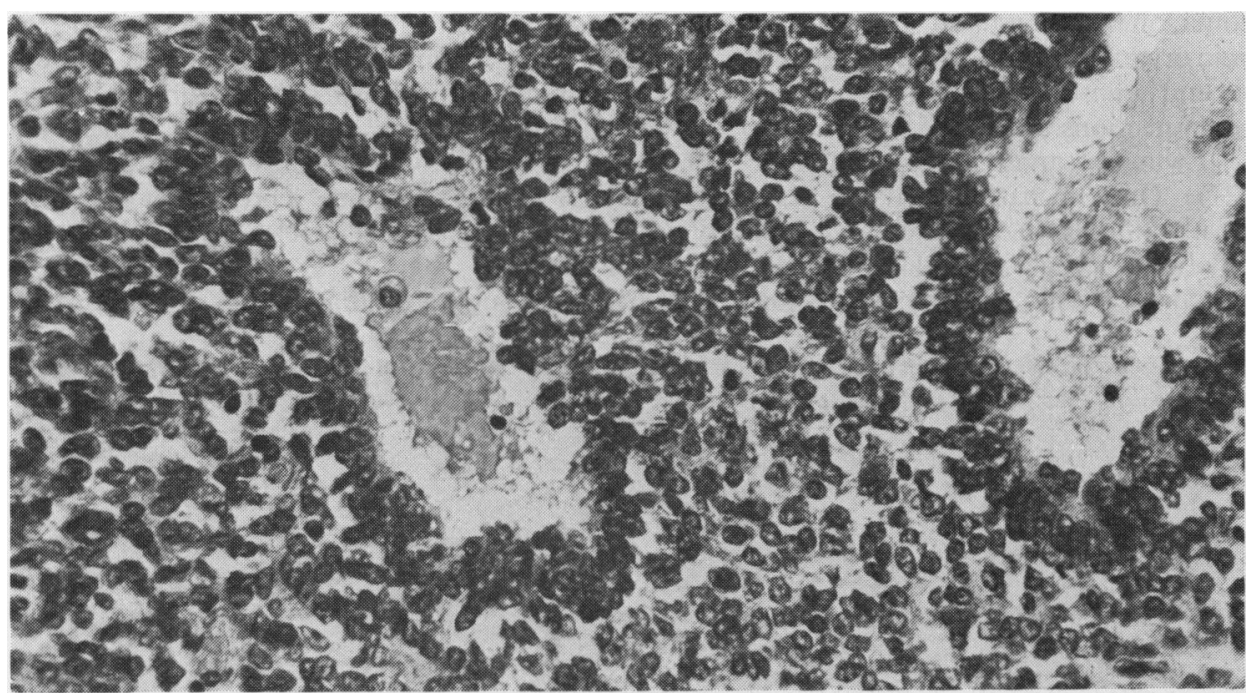

Fig. 4. Case 1. Light microscopical appearance of the sarcoma showing vascular channels within a uniform sheet of undifferentiated cells. $(H \& E \times 450$. $)$

from these blood-filled spaces where the neoplastic cells were arranged more densely, there was no recognisable pattern. The tumour cells were uniform with hyperchromatic ovoid nuclei and scanty cytoplasm. Mitotic figures were fairly frequent. Sections taken from different regions of the tumour varied only in respect to the degree of vascularity. In the more solid areas of the tumour the tissue was composed almost entirely of densely packed anaplastic cells. Elsewhere vascular channels were in close proximity to each other, some large enough to be identifiable on the cut surface of the gross specimen (Fig. 3). Interstitial haemorrhage within the solid parts of the tumour was common.

Electron microscopy. Ultrastructural examination of the tumours removed from Cases 3 and 4 was possible where tissue had been fixed in glutaraldehyde immediately after its surgical excision. The tumour cells were uniform, closely packed, with slightly irregular rounded nuclei. Scattered mitochondria, Golgi complexes, and a few small glycogen deposits were present within the cytoplasm. The plasma membranes of the tumour cells lacked desmosomes but in some areas a few pinocytotic vesicles could be identified (Fig. 5). The vascular spaces were formed by somewhat elongated tumour cells being aligned perpendicularly to the lumen (Fig. 6). The light and dark cell types which are a feature of Ewing's tumour were not evident. Some dark neoplastic cells were observed, but these were rare and not characteristic of either of the 2 tumours examined.

\section{Discussion}

All 4 children had a morphologically identical tumour. This was a small round cell sarcoma in which were distinctive vascular channels of variable size lined by tumour cells. In each case the tumour appeared to originate from the soft tissue of the chest wall and to erode bone or invade the lung secondarily. There is a possibility that, like Ewing's sarcoma, the tumour was subperiosteal in origin. On a histopathological basis also the similarity to Ewing's sarcoma may have led to this diagnosis being made in the past. Indeed in early reports relating to Ewing's sarcoma the endothelial origin of that tumour was the subject of debate. However, in a discussion of the histogenesis of Ewing's sarcoma Melnick (1933) categorically denied that it displayed any vasoformative differentiation. This view was subsequently confirmed by Ewing (1939) when he described the tumour to which he lent his name as a 'diffuse endothelioma'. Although this tumour displayed pseudorosettes and perithelial units Ewing distinguished it from angioendotheliomatous tumours in which definite blood channels could be recognised.

The ultrastructural studies that were performed confirm the histological impression that the present cases differed from a classical Ewing's tumour. Both of the chest wall sarcomas examined electron microscopically were composed of tumour cells rich in cytoplasmic organelles, with almost no glycogen, and completely deficient in desmosomes. The cells 
of a Ewing's sarcoma, on the other hand, are typically poor in cytoplasmic organelles and contain abundant glycogen (Kadin and Bensch, 1971). Intercellular desmosomal type connections are a common feature of the cells of Ewing's sarcoma (Povyšil and Matejovsky, 1977). Only occasional dark neoplastic cells were identifiable in the present cases, but distinct populations of light and dark tumour cells are a constant characteristic of Ewing's sarcoma
(Friedman and Gold, 1968; Nakayama et al., 1975). Steiner and Dorfman (1972) reported finding numerous pinocytotic vesicles in the tumour cells of a haemangioendothelial sarcoma of bone. The presence of pinocytotic vesicles in the chest wall sarcoma (Fig. 5) therefore lends support to an endothelial origin. Such vesicles are not seen in Ewing's tumour.

It has been suggested that Ewing's sarcomas are

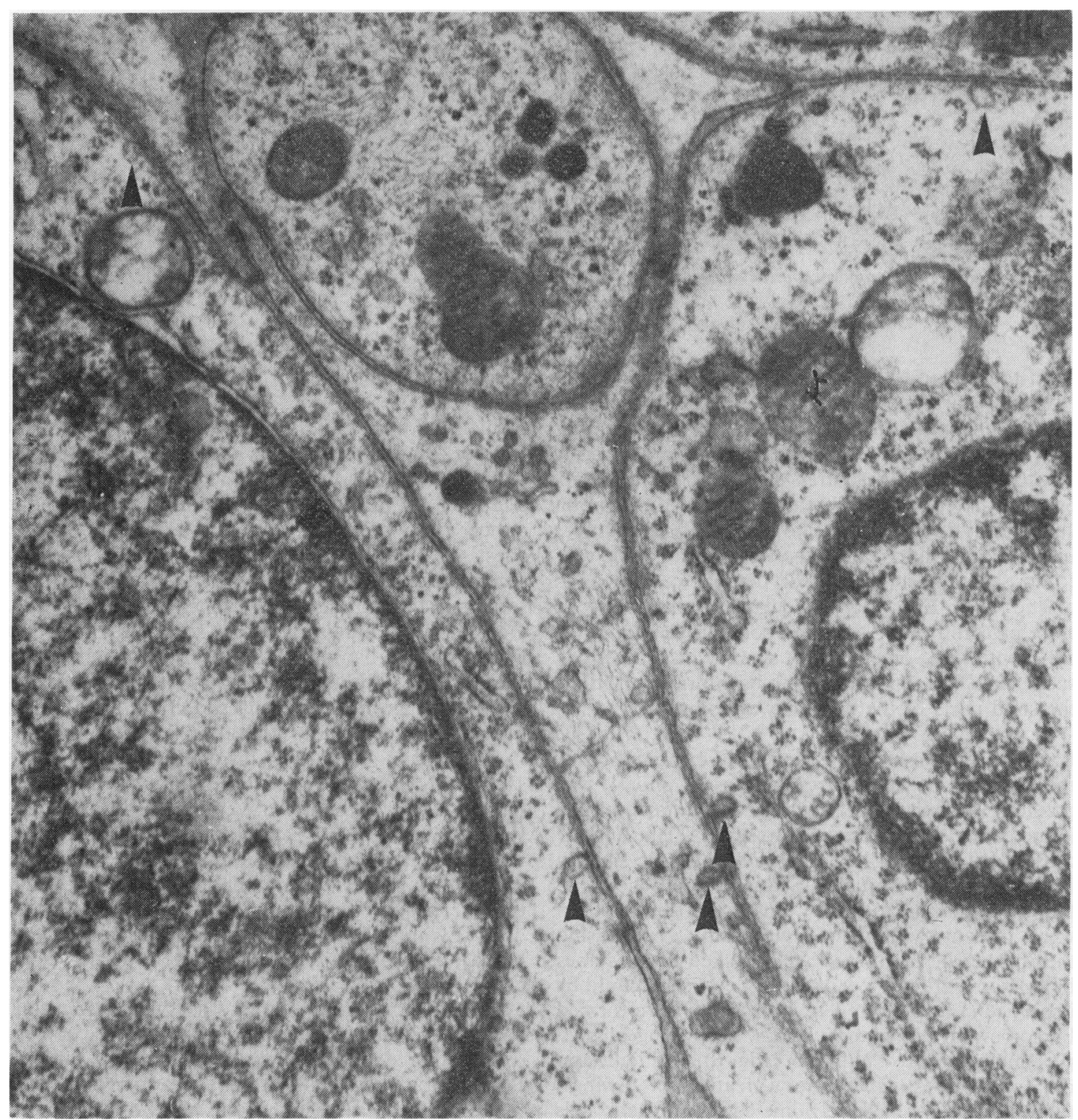

Fig. 5 Case 3. Neoplastic cells showing a variable population of cytoplasmic organelles. Cell membranes lack desmosomes but occasional pinocytotic vesicles (arrowed) are seen. $\times 30000$. 
not a homogeneous group of tumours. Oberling and Raileanu (1932) stated that Ewing's sarcoma arose from a primitive mesenchymal cell which was capable of differentiation towards blood-forming elements. An alternative view is that there exists an entity which has been termed a 'primitive multi-potential primary sarcoma of bone' (Hutter et al., 1966). Such a tumour is composed of undifferentiated cells which in different areas may show bone, cartilage, or vascular differentiation, or it may resemble a Ewing's sarcoma. It is of interest that in this series of 25 such tumours, 4 of the 5 longterm survivors had a basic histological pattern which resembled Ewing's sarcoma. More recently Angervall and Enzinger (1975) reported 39 small cell sarcomas histologically indistinguishable from Ewing's sarcoma of bone which were all extraskeletal in origin. Seven of these were located in the chest wall, mainly in the intercostal and subpleural connective tissue. However, as a group, these patients were older and had a worse prognosis than the 4 children in the present study.

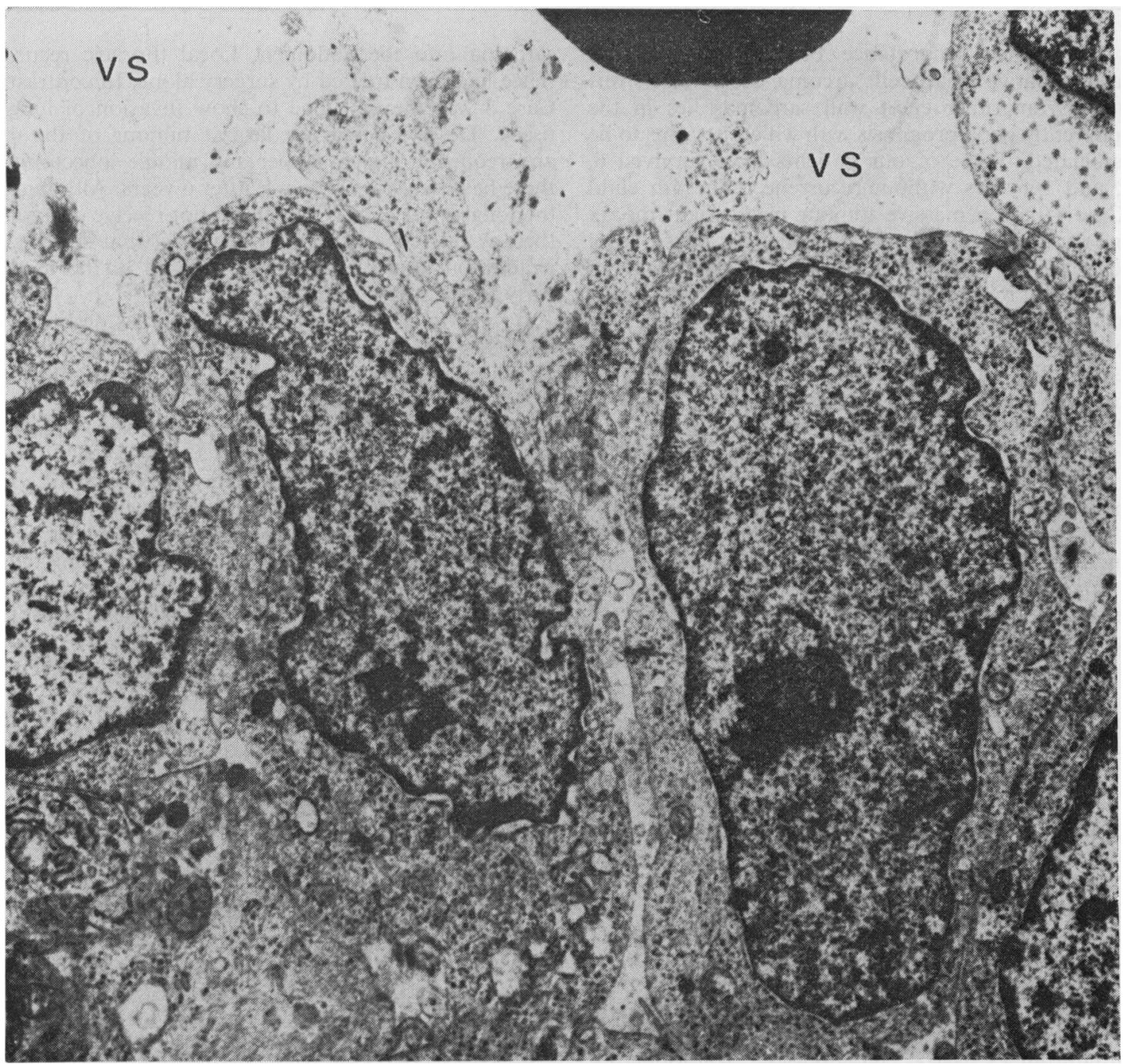

Fig. 6. Case 3. Electron microscopical appearance of neoplastic cells arranged perpendicularly to a vascular space (VS). $\times 10000$. 
Table Clinical features of 4 children with sarcoma of the chest wall

\begin{tabular}{|c|c|c|c|c|c|c|c|c|}
\hline Case & $\begin{array}{l}\text { Age at } \\
\text { presentation } \\
\text { (years) }\end{array}$ & $\begin{array}{l}\text { Duration of } \\
\text { symptoms } \\
\text { (months) }\end{array}$ & $\begin{array}{l}\text { Position } \\
\text { of tumour }\end{array}$ & $\begin{array}{l}\text { Size of } \\
\text { tumour } \\
\text { (diameter) }\end{array}$ & Surgery & Irradiation & Chemotherapy & Survival \\
\hline 1 & 14 & 6 & $\begin{array}{l}\text { Right 6th, } \\
\text { 7th, 8th ribs, } \\
\text { mid-zone }\end{array}$ & $7 \mathrm{~cm}$ & Yes & Yes & Yes & $\begin{array}{l}\text { Well } 8 \text { years } \\
\text { postoper- } \\
\text { atively }\end{array}$ \\
\hline 2 & 8 & 3 & $\begin{array}{l}\text { Right 5th rib, } \\
\text { anteriorly }\end{array}$ & $14 \mathrm{~cm}$ & Yes & Yes & No & $\begin{array}{l}\text { Well } 16 \text { years } \\
\text { postoper- } \\
\text { atively }\end{array}$ \\
\hline 3 & 11 & 2 & $\begin{array}{l}\text { Right thorax, } \\
\text { right 2nd and } \\
\text { 3rd ribs } \\
\text { anteriorly }\end{array}$ & $\begin{array}{l}800 \mathrm{~g} \\
7 / 8 \text { of } \\
\quad \text { right chest }\end{array}$ & Yes & Yes & Yes & $\begin{array}{l}\text { Well } 6 \text { years } \\
\text { postoper- } \\
\text { atively }\end{array}$ \\
\hline 4 & 8 & 2 & $\begin{array}{l}\text { Right } 5 \text { th, } 6 \text { th, } \\
\text { and } 7 \text { th ribs, } \\
\text { posteriorly }\end{array}$ & $\begin{array}{l}200 \mathrm{~g}, \\
11 \mathrm{~cm}\end{array}$ & $\begin{array}{l}\text { Yes, after } \\
4 \text { months' } \\
\text { chemotherapy }\end{array}$ & $\begin{array}{l}\text { Yes, after } \\
26 \text { months' } \\
\text { treatment }\end{array}$ & Yes & $\begin{array}{l}\text { Died } 29 \\
\text { months after } \\
\text { presentation }\end{array}$ \\
\hline
\end{tabular}

The clinical importance of differentiating the vasoformative small cell sarcoma described in this study from other chest wall sarcomas lies in the apparently good prognosis with which it seems to be associated. Three of our patients have survived 6 , 8 , and 16 years without recurrence. The 4 th child (Case 4) had a massive tumour in the right thorax and responded initially to chemotherapy and surgery; he survived almost $2 \frac{1}{2}$ years before death from abdominal metastasis. This is in contrast to a 5-year survival rate for Ewing's tumours of under $10 \%$ (Marsden and Steward, 1976). In an extensive search we could find no microphotograph of a tumour identical with the ones shown in Figs 1-6. However, Winham (1954) reported what was thought to be a unique case of a 10-year survival of a Ewing's tumour of a rib with a pulmonary metastasis presenting in a 15-year-old boy. Unfortunately the histology was distorted by preoperative irradiation but vascular spaces among sheets of a uniform small cell sarcoma can be recognised. It is only possible to say that this case has some resemblance to the ones in the present study.

The clinical presentation of our cases was not unlike that of other chest wall tumours. Localised pain was the predominant symptom in Cases 1 and 3 and Case 2 presented with a painless swelling. The 4th child was obviously seriously ill with dyspnoea and general malaise. All the tumours were large (Table). Three were treated by surgical resection followed by radiotherapy and, in two, also by chemotherapy. The most severely ill child (Case 4) was considered initially to be inoperable until a course of chemotherapy had reduced the size of the tumour. It is of interest that he was the only one not given radiotherapy immediately after primary surgical resection and who was treated initially by 15 weeks' chemotherapy. Radiotherapy was withheld until the terminal stage over 2 years later when there was paravertebral infiltration of sarcoma into the abdomen. Local thoracic recurrence had been treated by surgery alone. In contrast Case 3 was the only one to show invasion of lung tissue. Despite being the largest tumour of the 4 and requiring a right upper and middle lobectomy there has been no recurrence after 6 years. Although the longest survivor (Case 2) did not receive chemotherapy our experience would suggest that surgery, irradiation, and chemotherapy should all be used early in the treatment.

In our opinion the chest wall sarcomas described in these 4 children represent a distinct entity, mainly on the grounds of their histological and ultrastructural morphology, but also of their age incidence, location, and good prognosis. Their vasoformative differentiation is the most obvious feature distinguishing them from typical Ewing's sarcoma which in many other respects they closely resemble. They are locally invasive within the chest wall and erode adjacent ribs, but the bulk of the tumour usually protrudes as an encapsulated mass into the pleural cavity with compression of adjacent lung. Pulmonary infiltration and metastasis may occur but it is important to establish the correct diagnosis by biopsy since a vigorous policy of treatment by surgery, irradiation, and chemotherapy is fully justified even when the child is gravely ill.

We thank the Manchester Children's Tumour Registry for clinical information concerning Cases 1 and 3.

\section{References}

Angervall, L., and Enzinger, F. M. (1975). Extraskeletal neoplasm resembling Ewing's sarcoma. Cancer, 36, 240-251.

Ewing, J. (1939). A review of the classification of bone tumours. Surgery, Gynaecology, and Obstetrics, 68, 971-976.

Franken, E. A., Jr, Smith, J. A., and Smith, W. L. (1977). Tumors of the chest wall in infants and children. Pediatric Radiology, 6, 13-18. 
Friedman, B., and Gold, H. (1968). Ultrastructure of Ewing's sarcoma of bone. Cancer, 22, 307-322.

Hedblom, C. A. (1921). Tumors of the bony chest wall. Archives of Surgery, 3, 56-85.

Hochberg, L. A. (1953). Primary tumors of the rib. Archives of Surgery, 67, 566-594.

Hutter, R. V. P., Foote, F. W., Jr, Francis, K. C., and Sherman, R. S. (1966). Primitive multipotential primary sarcoma of bone. Cancer, 19, 1-25.

Joseph, W. L., and Fonkalsrud, E. W. (1972). Primary rib tumors in children. American Surgeon, 38, 338-342.

Kadin, M. E., and Bensch, K. G. (1971). On the origin of Ewing's sarcoma. Cancer, 27, 257-273.

Marsden, H. B., and Steward, J. K. (1976). Tumours in Children. Recent Results in Cancer Research, second edition, volume 13. Springer-Verlag: Berlin.

Melnick, P. J. (1933). Histogenesis of Ewing's sarcoma of bone. American Journal of Cancer, 19, 353-363.

Nakayama, I., Tsuda, N., Muta, H., Fujii, H., Tsuji, K., Matsue, T., and Takahara, D. (1975). Fine structural comparison of Ewing's sarcoma with neuroblastoma. Acta pathologica Japonica, 25, 251-268.

Oberling, C., and Raileanu, C. (1932). Nouvelles recherches sur les réticule-sarcomes de la moelle osseuse (sarcomes d'Ewing). Bulletin de l'Association français pour l'étude du cancer, 21, 333-347.

Pascuzzi, C. A., Dahlin, D. C., and Clagett, O. T. (1957). Primary tumors of the ribs and sternum. Surgery, Gynaecology, and Obstetrics, 104, 390-400.
Povýšil, C., and Matějovský, Z. (1977). Ultrastructure of Ewing's tumour. Virchows Archiv für pathologische Anatomie und Physiologie und für klinische Medizin, 374, 303-316.

Steiner, C. G., and Dorfman, H. D. (1972). Ultrastructure of hemangioendothelial sarcoma of bone. Cancer, 29, 122-135.

Teitelbaum, S. L. (1969). Tumours of the chest wall. Surgery, Gynecology, and Obstetrics, 129, 1059-1073.

Teitelbaum, S. L. (1972a). Twenty years' experience with intrinsic tumors of the bony thorax at a large institution. Journal of Thoracic and Cardiovascular Surgery, 63, 776-782.

Teitelbaum, S. L. (1972b). Twenty years experience with soft tissue sarcomas of the chest wall at a large institution. Journal of Thoracic and Cardiovascular Surgery, 63, 585-586.

Threlkel, J. B., and Adkins, R. B. (1971). Primary chest wall tumors. Annals of Thoracic Surgery, 11, 450-459.

Watkins, E., Jr, and Gerard, F. P. (1960). Malignant tumors involving the chest wall. Journal of Thoracic and Cardiovascular Surgery, 39, 117-129.

Winham, A. J. (1954). Ewing's tumor of a rib with pulmonary metastasis. Report of a case with a ten year survival. American Journal of Roentgenology, Radium Therapy, and Nuclear Medicine, 71, 445-447.

Correspondence to Dr A. J. Barson, Department of Pathology, The Medical School, University of Manchester, Oxford Road, Manchester M13 9PT.

The following articles will appear in future issues of this journal:

Werdnig-Hoffmann disease: the effects of intrauterine onset on lung growth. M. Cunningham and J. Stocks.

Hypothalamo-pituitary hormone insufficiency associated with cleft lip and palate. A. Roitman and Z. Laron.

Hypothyroidism in children with cystinosis. J. R. Burke, M. M. El-Bishti, M. N. Maisey, and C. Chantler.

Menkes's syndrome. Report of a patient treated from 21 days of age with parenteral copper. P. Daish, E. M. Wheeler, P. F. Roberts, and R. D. Jones.

Epileptic laughter with precocious puberty. M. Williams, W. Schutt, and D. Savage.

Depigmented hair. The earliest sign of tuberous sclerosis. R. C. McWilliam and J. B. P. Stephenson.

Acute anuric renal failure in an infant with systemic candidiasis. J. Z. Heckmatt, S. R. Meadow, and C. K. Anderson.

Bone growth in thalassaemic children. P. Lapatsanis, A. Divoli, H. Georgaki, S. Pantelakis, and S. Doxiadis. 